Check for updates

Cite this: Mater. Adv., 2020, 1,2407

Received 10th June 2020,

Accepted 26th August 2020

DOI: $10.1039 / \mathrm{d} 0 \mathrm{ma00404a}$

rsc.li/materials-advances

\section{Synthesis of stable gold nanoparticles using linear polyethyleneimines and catalysis of both anionic and cationic azo dye degradation $\uparrow$}

\author{
Ozge Cavuslar, ${ }^{a}$ Emre Nakay, ${ }^{b}$ Umut Kazakoglu, ${ }^{\text {b }}$ Sirous Khabbaz Abkenar, ${ }^{\circ}$ \\ Cleva W. Ow-Yang (iD cd and Havva Yagci Acar (iD *ab
}

\begin{abstract}
Reduction of auric acid with polyethyleneimine (PEI) provides a simple, low-cost alternative for the production of cationic gold nanoparticles (GNPS). However, linear PEI (IPEI) failed to produce small, colloidally stable GNPs, so far. Since IPEI is a polyelectrolyte, $\mathrm{pH}$ should be an important factor both in reduction and stabilization of GNPs and may be optimized to produce small and stable IPEI/GNPS. Cationic GNPs were produced by the direct reduction of auric acid in water with IPEI utilizing two different methods to dissolve the polymer: by protonation or at high temperature. The influence of $\mathrm{pH}$ on the particle formation and properties was studied over a wide $\mathrm{pH}$ range (3.5 to 10). The impacts of the PEl/Au mass ratio, polymer molecular weight $(2.5$ and $25 \mathrm{kDa})$ and post-synthetic $\mathrm{pH}$ on the particle properties were also studied. Best is to dissolve IPEI by protonation and to clean the GNPs via controlled centrifugal precipitation. The MW did not influence the hydrodynamic size, stability or particle shape, but low MW IPEI provided faceted particles. This simple one pot synthesis of small, stable cationic GNPs in water is a valuable, simple alternative for producing new cationic GNPs with even low molecular weight IPEI. Additionally, these GNPs were evaluated as catalysts in the degradation of methyl orange (MO) (anionic-zwitterionic) and methylene blue (MB) (cationic) azo dyes at different $\mathrm{pH}$ values. The fastest degradation of $\mathrm{MO}$ and $\mathrm{MB}$ was recorded at $\mathrm{pH} 7.5$ and 3.5, respectively. Overall, this is a rare case where a single catalyst quickly and effectively catalyzes the degradation of both cationic and anionic dyes.
\end{abstract}

\section{Introduction}

Gold nanoparticles (GNPs) are one of the most attractive and extensively studied materials of nanotechnology due to their unique size and shape dependent optical and electronic properties coupled with an inert nature, ${ }^{1,2}$ a high molar absorption coefficient and very high chemical and physical stability. ${ }^{3-5}$ They are investigated as catalysts, ${ }^{6,7}$ inks, ${ }^{8}$ conducting materials, sensors $^{7,8}$ etc. GNPs have been extensively utilized as catalysts in different applications such as cyclization, $\mathrm{C}-\mathrm{C}$ coupling, oxidation and reduction, including reduction of azo dyes. ${ }^{9-14}$ Due to their inert and non-toxic nature, they are frequently the preferred

\footnotetext{
${ }^{a}$ Koc University, Graduate School of Materials Science and Engineering, Rumelifeneri Yolu, Sariyer 34450, Istanbul, Turkey. E-mail: fyagci@ku.edu.tr; Tel: +90 2123381742

${ }^{b}$ Koc University, Department of Chemistry, Rumelifeneri Yolu, Sariyer 34450, Istanbul, Turkey

${ }^{c}$ Sabanci University, Material Science and Nano Engineering Program, Orta Mah. Universite Cad. No: 27, Tuzla, Istanbul 34956, Turkey

${ }^{d}$ Sabanci University Nanotechnology Research and Application Center (SUNUM), Orta Mah. Universite Cad. No: 27, Tuzla, Istanbul 34956, Turkey

$\dagger$ Electronic supplementary information (ESI) available. See DOI: 10.1039/d0ma00404a
}

nanomaterials for medical applications, as well. Aqueous, stable colloidal GNPs that are not heavily aggregated are needed for both medical and catalytic applications. The Turkevich method, the most widely used procedure to synthesize colloidal GNPs, produces large hydrophilic particles $(8-120 \mathrm{~nm})$ in aqueous media. ${ }^{15}$ For further applications, particles need to be capped with stabilizers for functionalization and to prevent aggregation. ${ }^{16}$ Organic coatings that are used to stabilize GNPs play a vital role in determining the size, shape, stability, and function of these nanoparticles. ${ }^{17,18}$

Organic coatings with amine functionality on nanoparticle surfaces are usually desirable for attachment or adsorption of active molecules to nanoparticles and/or further functionalization of the particle surface for specific duties. Polyethylenimine (PEI) is a popular amine-rich, cationic polymer, soluble in water, and widely used for a variety of applications. ${ }^{19}$ Its cationic nature allows complex formation with some metal ions, anionic molecules or polyelectrolytes. In medicine, PEI is accepted as the gold standard for non-viral gene delivery. ${ }^{20}$ Both linear and branched PEI may be used but its activity and toxicity depend on the molecular weight and branching. Linear and low molecular weight PEIs are usually more biocompatible. ${ }^{20}$ 
PEI coated metal nanoparticles have also been used for the degradation of anionic azo dyes. Azo dyes are one of the most favorable dye families for several industries such as food, textiles, paints, and pharma due to their structural and color diversity, low cost, easy product coloration, and excellent non-fade properties. ${ }^{21-25}$ Despite all the benefits, azo dyes are classified as genotoxic and carcinogenic agents. ${ }^{26,27}$ Their by-products cause serious environmental problems such as eutrophication $^{28}$ and prevention of aquatic photosynthesis because of absorbing and reflecting the sunlight in contaminated water. ${ }^{28-31}$ It was estimated that about $280 \mathrm{~K}$ tons of dye was released into the environment via industrial wastewater, which clearly demonstrates the need for effective wastewater treatment. ${ }^{32}$ Removing azo dyes from wastewater has been a significant concern for a long time. Indeed, metal nanoparticles have been used increasingly for the removal of several pollutants, including dyes, from water. ${ }^{33}$ Recently, metal nanoparticles, mostly silver, are being investigated for dye degradation. ${ }^{27,28,31,33-37}$ As the size of the nanoparticle decreases, the active sites on the NPs increase due to the large surface-to-volume ratio, and thus the reaction rate increases. ${ }^{9,38}$ Most studies focused on GNP-based catalytic degradation of azo dyes utilize GNPs synthesized in plant extracts, fungi or bacteria.9,24,27,31,36,39,40 However, controlling the particle size, shape, stability and size-distribution of biosynthesized GNPs is challenging. Yet, the stabilizing agent of GNPs plays an essential role in those properties and the activity/selectivity of catalysts on substrates due to the attractive or repulsive forces. ${ }^{17}$

PEI coated cationic nanoparticles are used for the separation and/or catalytic degradation of anionic dyes and pollutants. For example, Signori ${ }^{17}$ and Santos ${ }^{41}$ et al. used PEI coated silver nanoparticles stabilized with 2-chloroethanol or 1-bromooctane to increase the particle stability and demonstrated the catalytic reduction of $p$-nitrophenol. Long et al. used branched PEI (bPEI)-catechol coated superparamagnetic iron oxide nanoparticles (SPIONs) (500 $\mathrm{nm}$ in size) just for the selective removal of anionic dyes from a mixture of anionic-cationic dyes. ${ }^{42}$ Lie et al. modified silica nanoparticles with quaternized PEI for the adsorption of methyl orange (MO). Chem et al. utilized crosslinked bPEI bound $\mathrm{Fe}_{3} \mathrm{O}_{4}$ as a stable cationic adsorbent for selective removal of anionic dyes from model textile wastewater. ${ }^{43}$ On the other hand, anionic nanoparticles are used for cationic dyes, for example manganese oxide pyrolusite ${ }^{44}$ and carbondoped $\mathrm{TiO}_{2}$ at $\mathrm{pH} 7$ were utilized for methylene blue (MB). ${ }^{35}$ It would be quite advantageous to develop a catalytic system that can reduce both anionic and cationic dyes. Since PEI is a polyelectrolyte, we suggest that it may be used for the degradation of both anionic and cationic dyes at appropriate $\mathrm{pH}$ values, which would be quite a practical advantage. For such a purpose, we propose GNPs coated with linear PEI (IPEI), and even with low molecular weight lPEI, due to its safety. ${ }^{45}$ The GNP/IPEI composition would be attractive for medical applications, as well.

In a few studies, auric acid was reduced by citrate or ascorbic acid and then stabilized with linear PEI (IPEI). ${ }^{46,47}$ One straightforward way to achieve PEI-coated GNPs is the direct reduction of auric acid to GNPs by PEI. This was successfully shown in DMF and water with bPEI. ${ }^{48,49}$ Synthesis of other metal nanoparticles such as Pd and Pt with the DMF/PEI combination was also reported. ${ }^{50,51}$ Direct reduction of auric acid with IPEI was first reported by Sun et al. ${ }^{16}$ His study showed that gold nanoparticles, quasi-one-dimensional aggregates, and gold nanoplates can be formed by $423 \mathrm{Da}$ lPEI at $60{ }^{\circ} \mathrm{C}$ with a core size of the GNPs between 25 and $100 \mathrm{~nm}$. Kuo et al. reported that GNPs produced with IPEI coagulate and eventually precipitate. ${ }^{52}$ Hence, stabilization of IPEI-GNP is one of the main challenges. They have produced more stable GNPs by alkylating PEI to create polymer micelles, which prevented PEI chain entanglement. In another study, they modified IPEI with montmorillonite, which immobilized lPEI by restricting conformational changes. ${ }^{53}$ They were able to produce stable GNPs of 5 and $30 \mathrm{~nm}$ diameter. Kretschmer et al. also reported the reduction of auric acid by IPEI in DMF at $150{ }^{\circ} \mathrm{C}$, but the GNPs were aggregated during the synthesis. ${ }^{49}$

We are interested in production of small, colloidally stable IPEI-coated GNPs in a simple and reproducible way for both medical and catalytic applications, due to the non-toxic nature of the core and wide applicability coupled with low cytotoxicity of lPEI. However, conditions realizing such particles via direct reduction of auric acid with IPEI have not been understood, yet. In our previous study, we showed that bPEI successfully reduces auric acid in water and produces small, stable, cationic GNPs in one step. ${ }^{48}$ Here, we studied the one-step synthesis of GNPs via reduction of auric acid with lPEI in water and identified the dependence of the process and particle properties on the polymer molecular weight, $\mathrm{pH}$ and reaction time. IPEI is soluble in water only at low $\mathrm{pH}$ or at high temperature, unlike branched PEI. Therefore, the synthesis of GNPs by the dissolution of IPEI by both methods was studied here. Small, stable cationic GNPs were prepared for the first time with IPEI in water. Protonation and deprotonation of PEI is a valuable variable for both reduction, surface adsorption and stability. We primarily investigated the influence of the $\mathrm{pH}$, molecular weight of IPEI at a constant IPEI : Au mass ratio and reaction time on the particle properties. Additionally, we studied the impact of different mass ratios of IPEI/Au at a constant molecular weight and reaction time on the size and stability of GNPs. Hence, we have also studied the degradation of MB (cationic dye) and MO (anionic-zwitterionic) dyes at different $\mathrm{pH}$ values using IPEI-coated GNPs produced with 2.5 and $25 \mathrm{kDa}$ IPEI to elucidate the potential of these GNPs in catalytic degradation of cationic and anionic dyes.

\section{Experimental}

\section{Materials}

Gold(III) chloride solution (30 weight\%, 99.99\%) in dilute $\mathrm{HCl}\left(\mathrm{HAuCl}_{4}\right)$ was purchased from Aldrich (Germany). 2.5 and $25 \mathrm{kDa}$ linear polyethyleneimine (lPEI) (95-100\%) were purchased from Polyscience (USA). Centrifugal filters with $30 \mathrm{kDa}$ cut-off membranes were purchased from Sartorius. Sodium borohydride $\left(\mathrm{NaBH}_{4}, \mathrm{MQ100}\right)$ was purchased from Merck. Methyl orange (MO) (ACS reagent, 85\%) was purchased 
from Aldrich (Germany). Methylene blue (MB) (Reag. Ph Eur) was purchased from Aldrich (Germany).

\section{Instrumentation}

UV-vis absorption spectra were recorded on a Shimadzu UV-3600 spectrophotometer. To estimate the particle size, bright field transmission electron microscopy (TEM) images were taken on a Technai G2 F30 brightfield high resolution (HR) TEM (acceleration voltage $=200 \mathrm{kV}$ ) using samples deposited on a carbon coated Cu-grid from dilute solutions at UNAM (National Nanotechnology Research Center), Ankara, Turkey. To evaluate the faceting, high-resolution TEM (HRTEM) imaging was performed using $200 \mathrm{keV}$ electrons on a transmission electron microscope with a spherical aberration-corrected probe (JEOL JEM-ARM200CF). A Malvern Zetasizer Nano-ZS was used for determining the hydrodynamic size by dynamic light scattering (DLS) and for the measurement of the zeta potential. For X-ray photoelectron spectroscopy (XPS) and X-ray diffraction (XRD) analysis, IPEI-Au solutions were freeze-dried to obtain samples in the powder form. XPS analysis was performed on a Thermo Scientific K-Alpha XPS with Al $\mathrm{K} \alpha$ monochromatic radiation $(1486.3 \mathrm{eV})$. Powdered samples were put on carbon adhesive tape. A $50.0 \mathrm{eV}$ pass energy was used for the scans with a flood gun with a $400 \mathrm{~mm}$ spot size. A base pressure lower than $9 \times 10^{-9} \mathrm{mbar}$ and an experimental pressure of $1 \times 10^{-7} \mathrm{mbar}$ were achieved. The $\mathrm{C} 1 \mathrm{~s}$ peak at $284.5 \mathrm{eV}$ was used as a reference. For XRD measurements, powdered samples were placed on a silicon holder and analyzed with a D8 Advance Bruker instrument with $\mathrm{Cu} \mathrm{K} \alpha$ radiation $(\lambda=1.5406 \AA)$ between $2 \theta$ angles of $10^{\circ}$ and $80^{\circ}$.

\section{Synthesis of IPEI coated GNPs}

For the synthesis, a $\mathrm{HAuCl}_{4}$ stock solution was prepared by

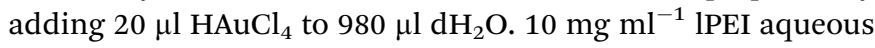
stock solution was prepared for each molecular weight. In Method-I, $10 \mathrm{mg}$ lPEI was added into $1 \mathrm{ml}$ deionized water and then acetic acid was added dropwise until all lPEI was dissolved. In Method-II, $10 \mathrm{mg}$ IPEI was added into $1 \mathrm{ml}$ deionized water and immersed in a preheated oil bath at $95{ }^{\circ} \mathrm{C}$ until all lPEI was dissolved. After the preparation of the stock solutions, reactions were performed in $20 \mathrm{ml}$ glass vials with a Teflon cap. Briefly, $200 \mu \mathrm{l}$ aqueous IPEI solution $\left(10 \mathrm{mg} \mathrm{ml}^{-1}\right)$ and $200 \mu \mathrm{HAuCl}_{4}$ stock solution were added into

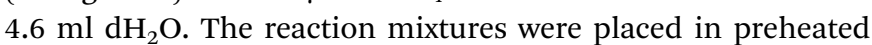
$\left(95{ }^{\circ} \mathrm{C}\right)$ silicon oil and stirred at a constant speed $(330 \mathrm{rpm})$ for about $30 \mathrm{~min}$. The change in the color of the reaction mixture from yellow to reddish indicates the reduction of gold from $\mathrm{Au}^{+3}$ to $\mathrm{Au}^{+1}$ to $\mathrm{Au}^{0}$. After cooling down the solutions to room temperature, the samples were transferred into falcon tubes and centrifuged for $30 \mathrm{~min}$ at $2500 \mathrm{rpm}$. The procedure was repeated three times and after each centrifugation the precipitated GNPs were removed. To isolate as many GNPs as possible without aggregation, aqueous GNPs were centrifuged at $4000 \mathrm{rpm}$ twice and at $6000 \mathrm{rpm}$ until the color of the solution turned light yellow. Centrifugation started at $2500 \mathrm{rpm}$ and was ramped gradually to the final rpm. Precipitated GNPs were collected in a separate vial covered with aluminium foil and diluted to the initial volume. The resulting GNP dispersions were stored at $4{ }^{\circ} \mathrm{C}$. The cleaning procedure was identical for the GNPs produced in Method-I and Method-II.

In order to investigate the effect of $\mathrm{pH}$ on the GNP synthesis, separate experiments were performed via Method-II. Before placing the reaction mixture into the preheated oil bath, its $\mathrm{pH}$ was adjusted with $0.5 \mathrm{M}$ sodium hydroxide or hydrochloric acid solution and it was mixed for 2 minutes at room temperature. The impact of the pH on the IPEI coated GNPs after synthesis and purification was also studied.

\section{Methyl orange and methylene blue degradation catalyzed by gold nanoparticles}

Degradation of methyl orange (MO) and methylene blue (MB) was performed with $\mathrm{NaBH}_{4}$ under the catalytic action of IPEI25-Au and IPEI2.5-Au synthesized with Method-I. Experiments were performed at room temperature under different $\mathrm{pH}$ conditions, i.e. $\mathrm{pH} 3.5$ and $\mathrm{pH} 7.5$.

Initially, $1967 \mu \mathrm{l} 8.54 \mu \mathrm{M}$ dye at $\mathrm{pH} 3.5$ or $\mathrm{pH} 7.5$ was added into a $3 \mathrm{ml}$ quartz cuvette and the absorption of the dye was recorded with a UV-vis spectrophotometer between $210 \mathrm{~nm}$ and $750 \mathrm{~nm}$. Then, $60 \mathrm{mM} \mathrm{NaBH}_{4}$ and $35.3 \mu \mathrm{l}(6 \mu \mathrm{g})$ GNP solution from $170 \mu \mathrm{g} \mathrm{ml}^{-1}$ GNP stock solution at a final volume of $2160 \mu \mathrm{l}$ were added, and an absorbance spectrum was taken and labelled as $t=0$. The time-dependent changes in the absorption peaks of the dyes were determined. For MO, the peak at $464 \mathrm{~nm}$ at $\mathrm{pH} 7.5$, and the peak at $500 \mathrm{~nm}$ at $\mathrm{pH} 3.5$ were used. In the case of MB the absorbance peak at $664 \mathrm{~nm}$ was used. Changes in the absorbance were recorded with $2 \mathrm{~min}$ intervals. The $\mathrm{pH}$ of the dye solutions was adjusted with $0.5 \mathrm{M}$ sodium hydroxide or hydrochloric acid solution.

Control experiments were performed with $7.88 \mu \mathrm{M}$ dye and $60 \mathrm{mM} \mathrm{NaBH}_{4}$ with a total volume of $2160 \mu \mathrm{l}$ in the absence of GNPs.

The \% dye degradation was calculated by the following equation:

$$
\% \text { dye degradation }=\frac{A_{0}-A_{t}}{A_{0}} \times 100 \%
$$

where $\left[A_{0}\right]$ is the initial concentration and $\left[A_{t}\right]$ is the concentration at time ' $t$ ' of the dye. To calculate the \% degradation of MO, the absorbance of the GNPs was normalized according to the MO absorbance at a wavelength where the GNPs did not have absorbance.

The recyclability of the GNPs as a catalyst was tested by adding a fresh sample of $3 \mathrm{mM}$ dye into the cuvette after full reduction of the first batch. When the degradation slowed down, $60 \mathrm{mM}$ freshly prepared $\mathrm{NaBH}_{4}$ was added to the same cuvette, followed by the addition of a new batch of $3 \mathrm{mM}$ dye in each cycle.

\section{Isothermal titration calorimetry (ITC) experiments}

ITC experiments were performed on a Nano ITC, TA Instruments, at $25{ }^{\circ} \mathrm{C} .7 .8 \mu \mathrm{M} \mathrm{MO}$ and $\mathrm{MB}$ prepared at $\mathrm{pH} 3.5$ and $\mathrm{pH} 7.5$ were injected into a $1 \mathrm{ml}$ sample cell in four separate experiments and 
$300 \mu \mathrm{l}$ of $600 \mu \mathrm{g} \mathrm{ml}^{-1}$ lPEI2.5-Au was loaded into a syringe. The dyes were titrated with 15 injections of $10 \mu \mathrm{l}$ GNPs with $10 \mathrm{~min}$ intervals under constant stirring. ITC experiments were also performed in the reverse order: $83.3 \mu \mathrm{g} \mathrm{ml} \mathrm{ml}^{-1}$ lPEI2.5-Au was added into a $1 \mathrm{ml}$ sample cell and $300 \mu \mathrm{l}$ of $160 \mu \mathrm{g} \mathrm{ml}^{-1}$ dyes at $\mathrm{pH} 3.5$ and 7.5 were loaded into the syringe in separate experiments. IPEI2.5-Au was titrated with 50 injections of $5 \mu \mathrm{l}$ dyes with 10 min intervals under constant stirring. The heat of reaction after each injection was recorded.

\section{Results and discussion}

\section{Synthesis and characterization of IPEI-GNP}

GNPs were synthesized in homogenous solutions of auric acid and IPEI. IPEI is soluble in water if it is acidified or heated. Both dissolution methods were used to investigate its influence on the formation of GNPs and their properties. In Method-I, wherein IPEI was dissolved in an acidic pH, an aqueous $25 \mathrm{kDa}$ lPEI solution and an auric acid solution were mixed at room temperature (RT) at a mass ratio of $1: 7$ and then placed into an oil bath at $95{ }^{\circ} \mathrm{C}$ for $20 \mathrm{~min}(\mathrm{pH}=3.2)$. The initial mixture had a characteristic yellow color due to the presence of $\mathrm{Au}^{+3}$, which slowly became red in the course of the reaction. Electron transfer from the amine groups of IPEI to $\mathrm{Au}^{+3}$ reduces $\mathrm{Au}^{+3}$ and produces metallic gold. This transformation was also followed with UV-vis spectroscopy. The red spectrum in Fig. 1a was collected from GNPs that were synthesized initially by using Method-I at an lPEI:Au mass ratio of 1:7. GNPs produced in an lPEI: Au ratio of $1: 3.5$ showed weaker absorbance at $520 \mathrm{~nm}$. Increasing the IPEI : Au ratio to $1: 21$ produced more GNPs, which were more monodisperse in size, showing a strong and narrower absorbance peak at $525 \mathrm{~nm}$ (Fig. 1a). Therefore, a 1:21 lPEI:Au mass ratio was used in the rest of this study. The mixture of aqueous auric acid and lPEI solution (IPEI/Au ${ }^{+3}$ ) had absorbance at $380 \mathrm{~nm}$ in both Method-I and Method-II. As the reduction was initiated, the characteristic surface plasmon band (SPB) of the GNPs appeared at around $520 \mathrm{~nm}$ in both synthetic methods, and the position and shape of the SPB were monitored during a $4 \mathrm{~h}$ reaction (Fig. 1 (b and c)).

In Method-I, acidification of IPEI protonates some of the secondary amine groups and causes chain extension, due to intra- and inter-chain charge repulsion. ${ }^{54}$ Protonation also reduces the number of amine groups that can donate electrons to reduce $\mathrm{Au}^{+3}$, while providing good electrostatic stability, hence providing small particles. Overall, it seems like such conditions successfully produce small and stable GNPs even at longer reaction times.

On the other hand, GNPs produced in Method-II had a SPB around $530-540 \mathrm{~nm}$, indicating larger or more aggregated particles at shorter reaction time compared to GNPs synthesized with Method-I. Still, the color stayed as a typical red color of GNPs (Fig. 1c).

In Method-II, although the lPEI stock solution is not acidified, the IPEI $/ \mathrm{Au}^{+3}$ solution had an initial reaction $\mathrm{pH}$ of 3.8 due to the acidic nature of the auric acid solution. Hence, the
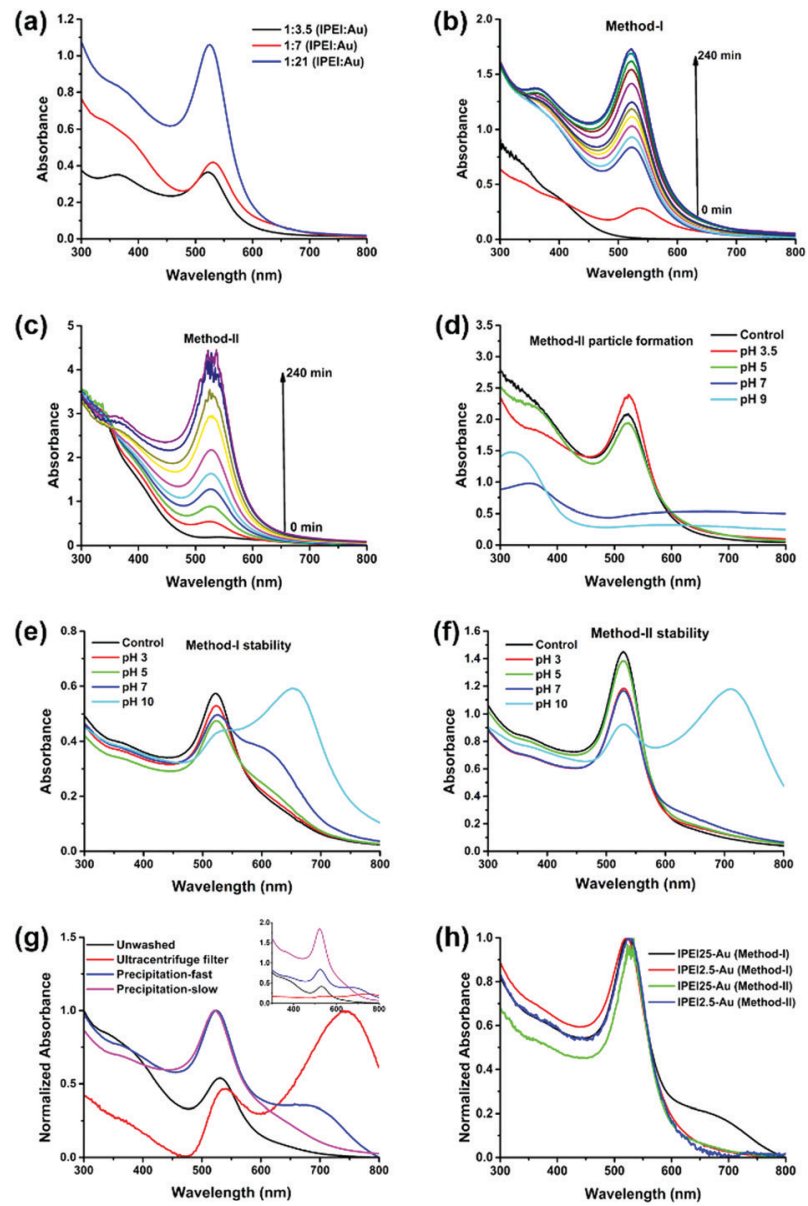

Fig. 1 Absorbance spectrum of unwashed GNPs synthesized (a) at different concentrations of $\mathrm{HAuCl}_{4}$, (b) at different reaction times with Method-I and (c) Method-II, and (d) at different reaction $\mathrm{pH}$ values with Method-II, and (e and f) synthesized by different methods and after cleaning and $\mathrm{pH}$ adjustment. The control spectrum represents no $\mathrm{pH}$ adjustment. (g) Normalized spectra of GNPs before and after purification utilizing different methods. The inset represents the unnormalized UV spectra. (h) GNPs synthesized with different molecular weights of PEI purified with the precipitation method.

protonation of IPEI should take place in Method-II, as well. To better observe the $\mathrm{pH}$ influence on particle formation, a series of reactions were conducted at different $\mathrm{pH}$ values at $95{ }^{\circ} \mathrm{C}$ using Method-II, because this method did not require $\mathrm{pH}$ adjustment for the dissolution of lPEI. The $\mathrm{pH}$ of the initial IPEI $/ \mathrm{Au}^{+3}$ mixture was set to $3.5,5,7$ and 9 with hydrochloric acid and sodium hydroxide while fixing all other parameters. Fig. 1d shows the absorption spectra of these GNPs after $30 \mathrm{~min}$ growth in comparison with the control, which was performed without $\mathrm{pH}$ adjustment (original $\mathrm{pH}=3.8$ ). GNPs were precipitated during the synthesis at $\mathrm{pH} 7$ and 9. GNPs produced in the controlled acidic pH (3.5 and 5) provided a slightly broader SPB, indicative of a more polydisperse size distribution, as shown in Table 1. This result suggests that the protonation of some amine groups is necessary for colloidal stability.

Furthermore, the influence of post-synthetic $\mathrm{pH}$ adjustment on the GNP stability and aggregation was studied (Fig. 1(e and f)). The typical $\mathrm{pH}$ of the reaction mixtures was 4.2 and 5.4 for 
Table 1 Influence of the $\mathrm{pH}, \mathrm{MW}$ and mass ratio on the properties of GNPs

\begin{tabular}{|c|c|c|c|c|c|}
\hline Sample name & $\begin{array}{l}\text { PEI } M_{\mathrm{w}} \\
(\mathrm{kDa})\end{array}$ & $\begin{array}{l}\text { PEI : Au } \\
\text { (weight ratio) }\end{array}$ & $\begin{array}{l}\text { Size }^{a} \\
{[\mathrm{~nm}]}\end{array}$ & $\mathrm{PDI}^{b}$ & $\begin{array}{l}\text { Zeta potential } \\
{[\mathrm{mV}]}\end{array}$ \\
\hline \multicolumn{6}{|c|}{ Particle formation } \\
\hline \multicolumn{6}{|c|}{ Method-I } \\
\hline Control-I & 25 & $1: 21$ & 31.53 & 0.33 & +44 \\
\hline lPEI2.5-Au & 2.5 & $1: 21$ & 24.12 & 0.22 & +51 \\
\hline \multicolumn{6}{|l|}{ Method-II } \\
\hline Control-II ${ }^{c}$ & 25 & $1: 21$ & 25.55 & 0.23 & +52 \\
\hline pH 3.5 & 25 & $1: 21$ & 52.42 & 0.43 & +53 \\
\hline pH 5 & 25 & $1: 21$ & 24.32 & 0.45 & +47 \\
\hline IPEI2.5-Au & 2.5 & $1: 21$ & 51.42 & 0.25 & +50 \\
\hline \multicolumn{6}{|c|}{ Post-synthetic particle properties } \\
\hline \multicolumn{6}{|c|}{ Method-I } \\
\hline pH 3 & 25 & $1: 21$ & 51.55 & 0.44 & +34 \\
\hline pH 5 & 25 & $1: 21$ & 46.10 & 0.47 & +31 \\
\hline pH 7 & 25 & $1: 21$ & 49.27 & 0.47 & +16 \\
\hline \multicolumn{6}{|l|}{ Method-II } \\
\hline pH 3 & 25 & $1: 21$ & 50.50 & 0.46 & +24 \\
\hline pH 5 & 25 & $1: 21$ & 41.62 & 0.41 & +38 \\
\hline pH 7 & 25 & $1: 21$ & 50.97 & 0.52 & +14 \\
\hline
\end{tabular}

Method-I and II, respectively, at the end of the reaction, when no $\mathrm{pH}$ adjustment was performed in Method-II. In the case of Method-I at and above $\mathrm{pH} 7$ and in the case of Method-II at pH 10, a second absorbance peak around $700 \mathrm{~nm}$ appeared due to aggregation. Deprotonation of amine groups causes interparticle $\mathrm{H}$-bonding and reduction of electrostatic repulsion; therefore, the particles were aggregated and precipitated.

Removing unbound chemicals from GNPs without causing aggregation or precipitation is always a challenge, but it is rarely mentioned in the literature. Two different methods were applied for the purification of the GNPs. First, the GNPs were washed in a $30 \mathrm{kDa}$ ultracentrifuge filter with DI water at $4000 \mathrm{rpm}$ for $20 \mathrm{~min}$. During this process, the color of the GNPs changed from red to purple-blue, indicating aggregation. The absorption peak of the GNPs seen at around $750 \mathrm{~nm}$ after ultrafiltration supports this observation (Fig. 1g). After some elapsed time, these GNPs precipitated. Alternatively, precipitation of GNPs via centrifugation was attempted. This approach requires delicate control of the speed. Some aggregation was observed at $6000 \mathrm{rpm}$ after $30 \mathrm{~min}$. Therefore, the best way is to start the process at $2500 \mathrm{rpm}$ and increase the speed gradually to $4000 \mathrm{rmp}$ and to $6000 \mathrm{rpm}$. The influence of the speed is clearly visible in Fig. $1 \mathrm{~g}$.

After optimizing the synthetic method and the washing procedure, the influence of the polymer molecular weight on the particle size and stability was also studied using $2.5 \mathrm{kDa}$ IPEI and $25 \mathrm{kDa}$ lPEI. Both samples were synthesized by Method-I and Method-II, and cleaned with the precipitation method (Fig. 1h). Even after the washing step, $2.5 \mathrm{kDa}$ IPEI induced the formation of more stable and smaller particles than $25 \mathrm{kDa}$ lPEI. This is quite a unique feature. Both lPEI25$\mathrm{Au}$ and IPEI2.5-Au maintained their colloidal stability over 2 years after synthesis. Fig. S1 (ESI $\dagger$ ) shows the absorbance spectra of fresh IPEI2.5-Au and 19 months after its synthesis.
No significant change in the absorbance profile or the position or intensity of the SPR peak was observed, suggesting a long shelf-life.

lPEI25-Au synthesized by Method-I was further characterized by XPS (Fig. 2a). Two different types of $\mathrm{N} 1 \mathrm{~s}$ were observed with binding energies (BEs) at ca. 399 and $400 \mathrm{eV}$. The amount of bound or oxidized amines with BE at $c a .400 \mathrm{eV}$ is about $72 \%$ of all amines. Moreover, three types of C 1s with BEs at ca. 284.6, 285.9 and $287.5 \mathrm{eV}$ were observed. Carbons with BEs at 285.9 and $287.5 \mathrm{eV}$ correspond to $\mathrm{C}-\mathrm{N}$ and $\mathrm{C}=\mathrm{N}$, respectively. The formation of imide bonds was also observed with bPEI in our previous study. ${ }^{48}$ Kretschmer et al. also mentioned the formation of imide during the hightemperature reduction of gold with branched PEI. ${ }^{49}$ The BE of $\mathrm{Au} 4 \mathrm{f}^{7}$ at $\mathrm{ca} .84 \mathrm{eV}$ indicates that $\mathrm{Au}$ is in its metallic state. The X-ray diffraction pattern of the GNPs is consistent with the face-centered-cubic (FCC) crystalline structure of gold with diffraction peaks at $38.3,44.4,64.7,77.6$, and 81.8 degrees corresponding to the (111), (200), (220), (311) and (222) planes (Fig. 2b). ${ }^{55}$

In order to estimate the particle size, bright field TEM images of GNPs prepared by Method-I were taken (Fig. 3(a-d)). IPEI2.5-Au nanoparticles are $15 \pm 4 \mathrm{~nm}$ in diameter and lPEI25$\mathrm{Au}$ nanoparticles are $14.3 \pm 3.4 \mathrm{~nm}$ (Fig. 3(b-d)). For functionalized GNPs synthesized by Method-I (IPEI dissolved in acidic $\mathrm{pH}$ ), HRTEM phase contrast images revealed faceted structures and suppression of faceting when the lPEI molecular weight increased from $2.5 \mathrm{kDa}$ to $25 \mathrm{kDa}$ (Fig. 3(e and f)). Delocalization effects of the coherent illumination probe can be observed on the air side of the particles. The diminished faceting tendency due to high molecular weight lPEI suggests that the kinetics of surface diffusion are more limited. Under acidic conditions, in which there are fewer amine groups available to reduce $\mathrm{Au}^{3+}$, and to pacify the growing crystal, the lower concentration of $\mathrm{Au}^{0}$ adsorbing on the nanoparticle surface seeks the position of lowest free energy, which is dominated by enthalpy changes or forming the most bonds, by migrating to kink sites on ledges. The molecular weight dependence under acidic conditions may be due to the higher concentration of amine groups per chain increasing the flux of

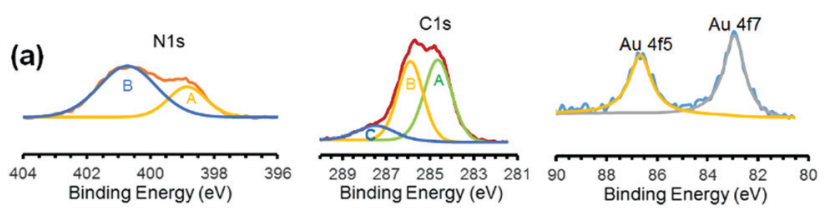

(b)

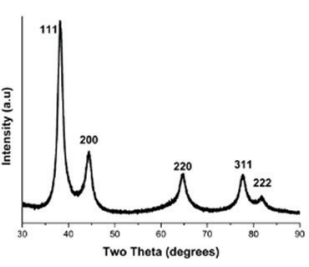

Fig. 2 (a) XPS spectra of IPEI25-Au prepared at a 21:1 (Au: PEI) mass ratio synthesized with Method-I. (b) X-ray diffraction pattern of IPEI25-Au that was synthesized with Method-I, at a 21:1 (Au: PEI) mass ratio. 
(a)

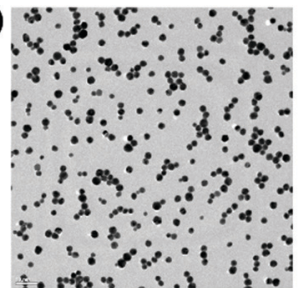

(c)

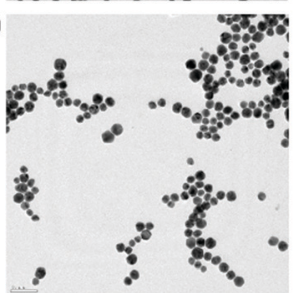

(e)

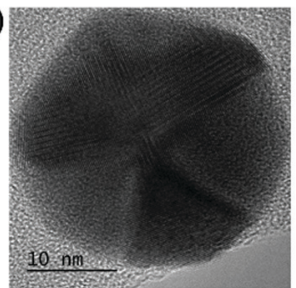

(b)

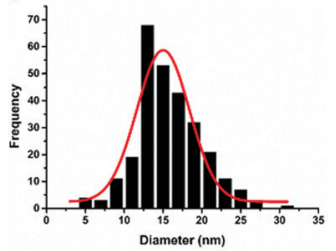

(d)

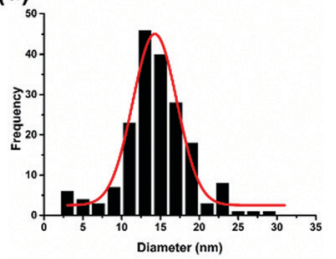

(f)

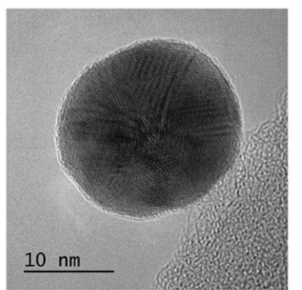

Fig. 3 Bright field TEM images of and size distribution of IPEI2.5-Au ( $a$ and b) and IPEI25-Au ( $\mathrm{c}$ and d) nanoparticles. Size distribution of (b) IPEI2.5-Au and (d) IPEI25-Au nanoparticles calculated from images (a) and (c), respectively. HRTEM phase contrast images of (e) IPEI2.5-Au and (f) IPEI25-Au nanoparticles. Both samples were prepared at a 21:1 (Au : PEI) mass ratio, synthesized with Method-I.

atoms and may be due to slight conformational changes. The effect of the IPEI molecular weight on faceting is diminished when lPEI-functionalized GNPs were synthesized using Method-II (lPEI dissolved at $95{ }^{\circ} \mathrm{C}$ ). The chemical activity of lPEI dissolved in neutral water by heating would be higher than the protonated lPEI of Method-I, providing a high flux of atoms, which hinders the diffusion of gold atoms to the lowest energy positions, and adatoms adsorb randomly.

\section{Catalytic reduction of MO}

The ability of IPEI25-Au and IPEI2.5-Au (synthesized by Method-I) nanoparticles to catalyze the degradation of MO was investigated. MO is extensively used in different areas from textiles to the pharmaceutical industry. ${ }^{56,57}$ Since it is a cancerogenic dye, its removal from wastewater is essential. It is an anionic molecule in aqueous media $(\mathrm{pH} \sim 7)$, but at $\mathrm{pH} 3.5$ (pKa 3.4) it is zwitterionic due to the protonation of its azo functional group $(-\mathrm{N}=\mathrm{N}-)$ as shown in Fig. $4 a^{28,58}$ Therefore, we studied its degradation at $\mathrm{pH} 3.5$ and 7.5. In a typical experiment, $7.8 \mu \mathrm{M}$ MO was reduced with $60 \mathrm{mM} \mathrm{NaBH}_{4}$ in the presence of $6 \mu \mathrm{g}$ GNPs at room temperature. The dye degradation was monitored from the changes of the MO absorption peak as shown in Fig. $4 \mathrm{~b}$ for MO degradation at $\mathrm{pH}$ 7.5. The blank spectrum represents the absorbance of MO at $\mathrm{pH}$ 7.5. The absorbance recorded after addition of $33 \mu \mathrm{l}$ $60 \mathrm{mM} \mathrm{NaBH} 4$ was considered as $t=0 \mathrm{~min}$ and the change in the peak intensity of the dye was recorded every 2 min for a

(a)
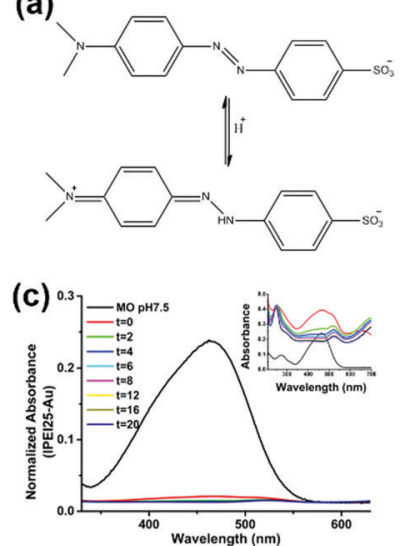

(d)

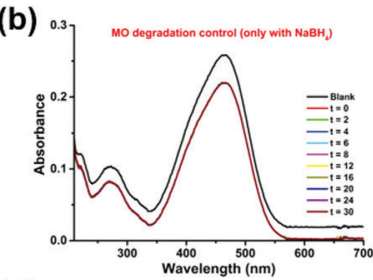

(e)

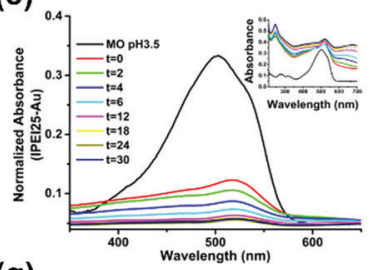

(g)

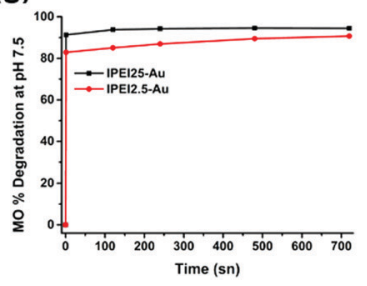

(h)
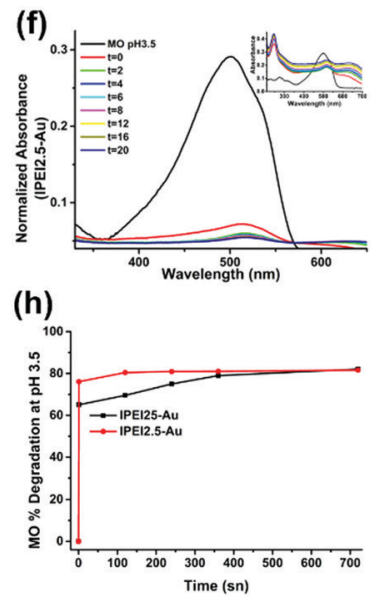

Fig. 4 (a) Ionization of MO under acidic conditions. UV-vis absorption spectrum of time dependent degradation of $M O(b)$ in the absence of GNPs. Normalized UV-vis absorption spectra of time dependent degradation of $\mathrm{MO}$ between 350 and $650 \mathrm{~nm}$ ( $\mathrm{c}$ and d) at $\mathrm{pH} 7.5$ with IPEI25-Au and IPEI2.5- $\mathrm{Au}$, and (e and f) at pH 3.5 with IPEI25-Au and IPEI2.5- $\mathrm{Au}$ (the inset shows the absorbance spectra between 210 and $700 \mathrm{~nm}$ ). ( $\mathrm{g}$ and $\mathrm{h}$ ) \% degradation of $\mathrm{MO}$ at $\mathrm{pH} 7.5$ and $\mathrm{pH} 3.5$ with IPEI25-Au and IPEI2.5-Au.

total of $30 \mathrm{~min}$ in the absence of GNPs. No MO degradation was detected. Although $\mathrm{NaBH}_{4}$ is a strong reducing agent, its aqueous solution is incapable of degrading the dye molecule efficiently without a catalyst. ${ }^{12,37}$ Addition of $6 \mu \mathrm{g}$ GNPs in solution initiated the reduction by facilitating the electron transfer from $\mathrm{BH}_{4}{ }^{-}$to the dye molecule (Fig. 4). The degradation lasts until $\mathrm{BH}_{4}{ }^{-}$is consumed. In Fig. 4(c-f), degradation of MO performed at $\mathrm{pH} 3.5$ and 7.5 with both IPEI25-Au and IPEI2.5-Au is shown with the normalized absorbance graphs and the absorbance spectrum (as the inset) between 210 and $700 \mathrm{~nm}$. The absorbance peak of MO is at $465 \mathrm{~nm}$ at pH 7.5 and at $500 \mathrm{~nm}$ at $\mathrm{pH} 3.5$ due to the protonation of the azo group. These absorbance peaks of MO disappeared because of the cleavage of the azo functional group $(-\mathrm{N}=\mathrm{N}-)$ and a new peak at $243 \mathrm{~nm}$ appeared, indicating the formation of degradation products (Fig. 4). Besides, a new absorbance peak around 600-700 nm was observed in all four graphics, which is interpreted as aggregation of GNPs. This is in agreement with the aggregation of GNPs detected at pH 7.5 (Fig. 4(c-f)). Yet, these results indicate that such aggregation does not hinder the 
catalytic activity of GNPs in MO degradation. Typically, we do not expect aggregation of GNPs at pH 3.5 due to strong cationic surface charge; however, a little aggregation is suggested by the weak absorbance at around $600-700 \mathrm{~nm}$ again. The adsorption of $\mathrm{MO}$ (zwitterionic at this $\mathrm{pH}$ ) and maybe degradation products on GNPs may cause secondary interactions resulting in aggregation. Overall, the GNPs managed to reduce MO at both $\mathrm{pH}$ values successfully, but the MO degradation was faster at pH 7.5 than pH 3.5 with both GNPs. Even though GNPs interact with methyl orange electrostatically, at $\mathrm{pH} 3.5$ protonation of most secondary amines of IPEI may reduce the electron transfer from $\mathrm{BH}_{4}{ }^{-}$to $\mathrm{MO}$.

The MO degradation amount was calculated from the normalized absorbance data. Fig. $4(\mathrm{~g}$ and $\mathrm{h})$ shows that the degradation of MO at $\mathrm{pH} 7.5$ was $91 \%$ with IPEI25-Au and $83 \%$ with IPEI2.5-Au right after addition, reaching a total degradation of $90 \%$ in $12 \mathrm{~min}$. On the other hand, the degradation of $\mathrm{MO}$ at $\mathrm{pH} 3.5$ was $65 \%$ with lPEI25-Au and $76 \%$ with IPEI2.5-Au. This may be at least partially due to some aggregation of the former particles.

\section{Catalytic reduction of MB}

Methylene blue (MB) is a cationic thiazine and is another widely utilized dye in the chemical and medicinal industry. ${ }^{59,60}$ The resonance structures of methylene blue are presented in Fig. 5a. Similar to $\mathrm{MO}, \mathrm{NaBH}_{4}$ alone was not sufficient to reduce MB (Fig. 5b) in considerable amounts in the absence of GNPs. MB has absorbance peaks at 290 and $664 \mathrm{~nm}$ with a shoulder at $612 \mathrm{~nm}$ due to $\pi$ to $\pi^{*}$ and $\mathrm{n}$ to $\pi^{*}$ transitions. As seen in Fig. 5(c-f), upon addition of GNPs to $\mathrm{MB} / \mathrm{NaBH}_{4}$, reduction of the dye starts quickly as indicated by the decrease in the intensity of the absorbance peak at $664 \mathrm{~nm}$ and the appearance of a new peak at $257 \mathrm{~nm}$ attributed to the formation of leuco methylene blue (Fig. 5). ${ }^{36}$ The absorbance at $600-700 \mathrm{~nm}$ during the reduction is again interpreted as a small amount of GNP aggregation. Both MB and GNPs are cationic. MB is cationic both at $\mathrm{pH} 7.5$ and 3.5. The cationic charge on GNPs is higher at pH 3.5 than 7.5 (Table 1). One may think that cationic GNPs would repel the cationic dye, reducing the catalytic activity. However, Fig. $5 \mathrm{~g}$ shows that the degradation of $\mathrm{MB}$ at $\mathrm{pH} 7.5$ was $91.5 \%$ with both lPEI25-Au and IPEI2.5-Au immediately after addition of GNPs to the dye. At pH 3.5 almost complete degradation of MB (99.4\%) with IPEI25-Au and $97.5 \%$ with lPEI2.5-Au were achieved as soon as the GNPs were added (Fig. $5 \mathrm{~h}$ ). These results indicate no significant influence of the lPEI molecular weight and better catalytic activity at $\mathrm{pH}$ 3.5. Here, $\mathrm{MB}$ is reduced with a cationic catalyst for the first time to the best of our knowledge. At pH 7.5 methylene blue is still cationic, yet IPEI is partially deprotonated as suggested by the lower zeta potential (Table 1).

Hence, the possible charge repulsion may be less, but such strong reduction may not be simply explained by this. Lone pair (lp) to $\pi$ stacking interactions between aromatic rings of $\mathrm{MB}$ and lone pair electrons of lPEI may be considered as the attractive force between MB and GNPs. ${ }^{61,62}$ At pH 3.5 GNPs would have a more substantial charge, but cation to $\pi$ interactions may take place as a favorable non-covalent interaction. (a)
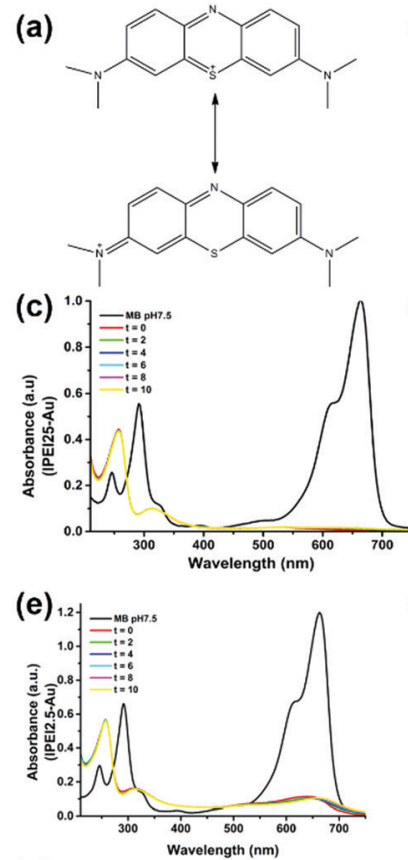

(g)

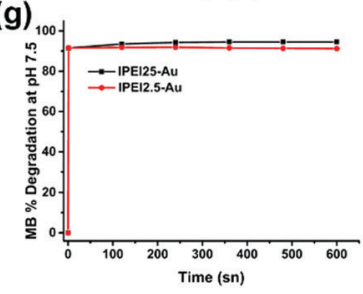

(b)

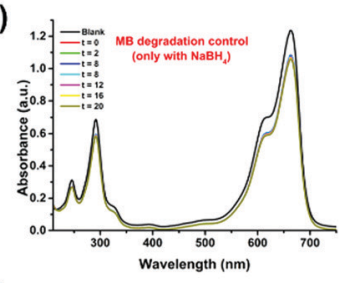

(d)

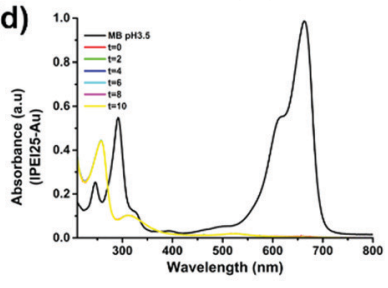

(f)

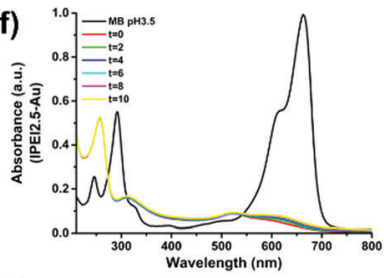

(h)

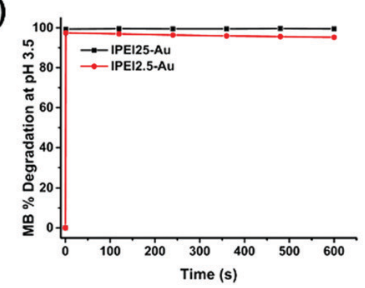

Fig. 5 (a) Ionization of MB under acidic conditions. UV-vis absorption spectrum of time dependent degradation of MB between 210 and $750 \mathrm{~nm}$ (b) in the absence of GNPs, ( $\mathrm{C}$ and d) at pH 7.5 with IPEI25-Au and IPEI2.5-Au, and (e and f) at $\mathrm{pH} 3.5$ with IPEI25-Au and IPEI2.5-Au. ( $\mathrm{g}$ and $\mathrm{h}$ ) \% degradation of $\mathrm{MB}$ at $\mathrm{pH} 7.5$ and $\mathrm{pH} 3.5$ with IPEI25-Au and IPEI2.5-Au.

\section{Investigation of dye-GNP interactions by ITC}

The electrostatic interactions between dye molecules and GNPs were further investigated with isothermal titration calorimetry (ITC). The reaction thermodynamics and kinetics can be quantitatively determined by ITC..$^{63} 1 \mathrm{ml} 7.8 \mu \mathrm{M}$ MO was added into the titration cell, and was titrated with 15 portions of $10 \mu \mathrm{l}$ GNPs with $10 \mathrm{~min}$ intervals. After each titration, an exotherm was detected, indicating the binding of both dyes at both $\mathrm{pH}$ values (pH 3.5 and 7.5) to the GNPs (Fig. 6(a-d)). ${ }^{64}$ Such an interaction supports the degradation of both dyes at both $\mathrm{pH}$ values. The interaction between IPEI2.5-Au and MO at $\mathrm{pH} 7.5$ was the strongest, where the GNPs were cationic, and MO is anionic. The lower binding exotherm at $\mathrm{pH} 3.5$ can be explained by the charge repulsion between MO and IPEI2.5$\mathrm{Au}$. Although the interactions are weak, they seem to be sufficient to aid electron transfer from borohydride to the dyes via GNPs (Fig. 7).

When the dye was titrated with gold nanoparticles, the exotherm magnitudes are not very different between MB and MO. However, if gold is titrated with the dye, the difference between the interaction of MO and MB with the GNPs is more 


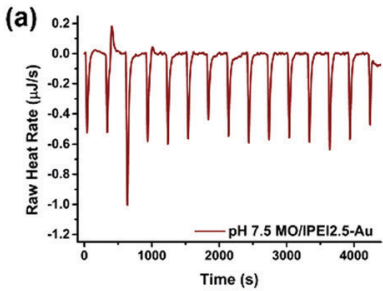

(c)

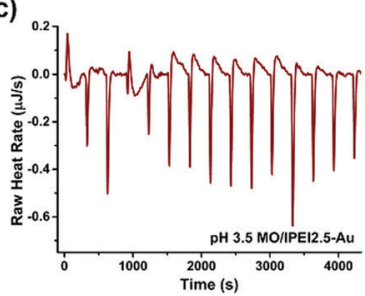

(e)

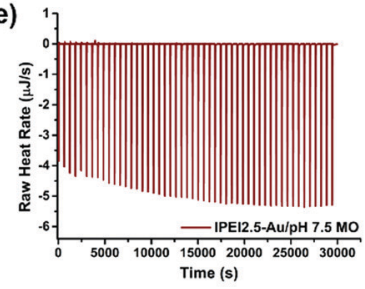

(g)

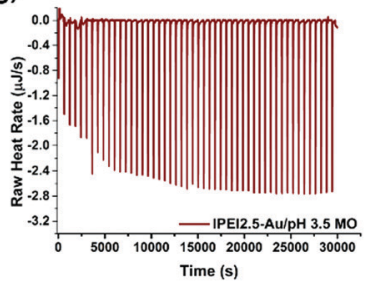

(b)

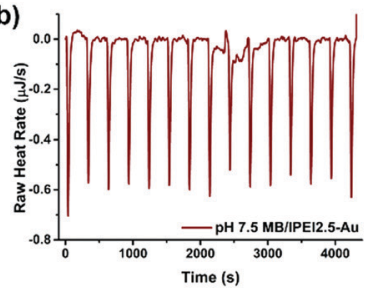

(d)

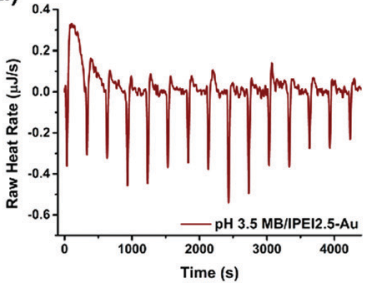

(f)

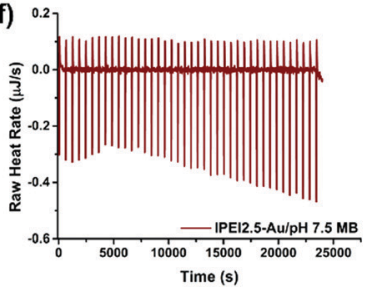

(h)

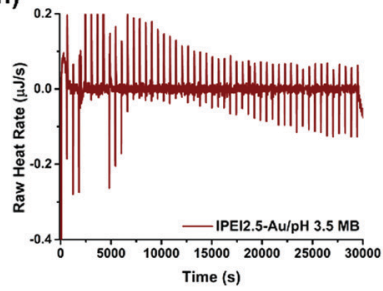

Fig. 6 Baseline subtracted raw data for the ITC titration of (a) $\mathrm{MO}$ at $\mathrm{pH}$ 7.5, (b) $\mathrm{MB}$ at $\mathrm{pH} 7.5$, (c) $\mathrm{MO}$ at $\mathrm{pH} 3.5$, and (d) $\mathrm{MB}$ at $\mathrm{pH} 3.5$ with IPEI2.5-Au and titration of IPEI2.5-Au with (e) $\mathrm{MO}$ at $\mathrm{pH} 7.5$, (f) $\mathrm{MB}$ at $\mathrm{pH} 7.5$, (g) $\mathrm{MO}$ at $\mathrm{pH} 3.5$, and (h) $\mathrm{MB}$ at $\mathrm{pH} 3.5$.

visible (Fig. $6(\mathrm{e}-\mathrm{h})) .1 \mathrm{ml}\left(83.3 \mu \mathrm{g} \mathrm{ml}^{-1}\right)$ GNPs were added into a sample cell and $300 \mu \mathrm{l}$ of $160 \mu \mathrm{g} \mathrm{ml}^{-1}$ dye was loaded into a syringe. IPEI2.5-Au was titrated with 50 portions of $5 \mu \mathrm{l}$ dyes with 10 min intervals. Strong exotherms were detected with MO due to attractive charge interactions, as expected. On the other hand, much smaller exotherms with some endotherms were observed with MB. This is more in line with our expectations considering the charge of the particles and the dye. Some electrostatic charge repulsion is expected, which is more dramatic at $\mathrm{pH}$ 3.5. However, also some attraction still exists between MB and GNPs, which is most probably in the form of cation $-\pi$ and/or lone pair electron- $\pi$ interactions, as discussed above (Fig. 7).

\section{Recyclability of the GNPs}

The recyclability of IPEI25-Au was tested in methyl orange degradation at $\mathrm{pH} 7.5$ in the presence of $60 \mathrm{mM} \mathrm{NaBH}_{4}$. In each cycle, a fresh sample of the dye at the same amount was added. In the first 8 cycles, the degradation was around $90 \%$ (Fig. 8a), and it dropped to $\sim 60 \%$ in the 9 th cycle. The addition of a new batch of $60 \mathrm{mM} \mathrm{NaBH}_{4}$ improved the degradation to

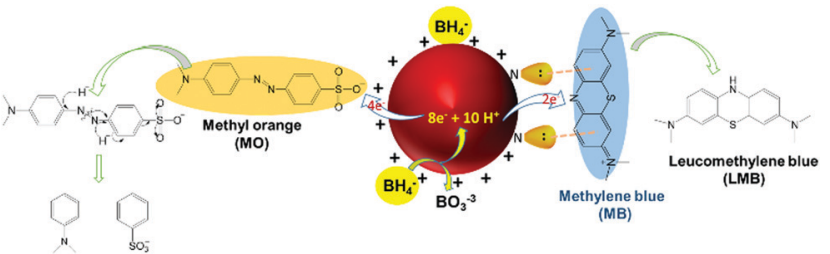

Fig. 7 Schematic representation of $M O$ and MB degradation by cationic GNPs.
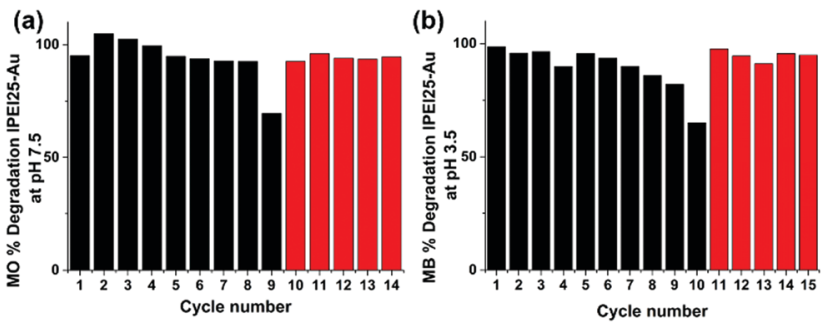

Fig. 8 Recyclability of IPEI25-Au in dye degradation of (a) MO at pH 7.5 and (b) $\mathrm{MB}$ at $\mathrm{pH} 3.5$.

$90 \%$ again (10th cycle), indicating that the catalyst is still active. For the next 5 cycles, the activity was back around $90 \%$. A similar experiment was performed with methylene blue at pH 3.5, and a very similar trend was observed (Fig. 8b). These results suggest that the GNPs are stable and recyclable in this process.

\section{Conclusions}

Reproducible, cationic gold nanoparticles (GNPs) were produced by the direct reduction of auric acid in water, with linear polyethylenimine (lPEI), using two different synthetic protocols-one in which lPEI is dissolved by heating, and the other by acidification. The influence of $\mathrm{pH}$ on the particle formation and stability was studied between $\mathrm{pH} 3.5$ and 10 for the first time for IPEI/GNP. This study shows that the protonation of some amine groups is necessary for colloidal stability, and it does not prevent the reduction of auric acid to GNPs. This approach also made it possible to synthesize colloidally stable gold nanoparticles in small hydrodynamic sizes with low molecular weight lPEI ( $2.5 \mathrm{kDa})$, as well as $25 \mathrm{kDa}$ IPEI. The mass ratio of IPEI/Au was also studied. We propose Method-I, wherein IPEI was dissolved by acidification, and a lPEI/Au ratio of $1 / 21$ as the best approach and a careful centrifugal precipitation procedure as a safe cleaning protocol to produce small and stable, colloidal IPEI/GNP. For storage purposes, we also suggest an acidic pH. Although the molecular weight of IPEI did not influence the size and the stability much, which may be surprising, HRTEM images revealed faceted crystals for $2.5 \mathrm{kDa}$ lPEI coated GNPs. However, the tendency for faceting decreased with increasing MW during GNP formation when lPEI was dissolved in low $\mathrm{pH}$; the MW dependence of the GNP shape was negligible when IPEI was dissolved at high temperature. This simple one-pot synthesis of cationic 
GNPs in water is a valuable, simple alternative for the generation of new cationic GNPs in water with even low molecular weight PEI. These GNPs were also demonstrated as an efficient catalyst for the degradation of both anionic and cationic azo dyes, which is unique in the literature, presenting potential as a universal catalyst. Electrostatic attraction, as well as cation $-\pi$ and lone pair electron- $\pi$ interactions, is suggested as the reason behind such universal action of these GNPs. The recyclability of these GNPs also increases their value and potential in industrial applications as an environmentally friendly catalyst.

\section{Conflicts of interest}

There are no conflicts to declare.

\section{Acknowledgements}

We would like to thank Dr Ceren Yilmaz Akkaya and Dr Barış Yağcı (KUYTAM, Koc University) for the XRD and XPS analysis.

\section{References}

1 J. Chung, S. Ko, N. R. Bieri, C. P. Grigoropoulos and D. Poulikakos, Conductor microstructures by laser curing of printed gold nanoparticle ink, Appl. Phys. Lett., 2004, 84, 801-803.

2 M.-C. Daniel and D. Astruc, Gold nanoparticles: assembly, supramolecular chemistry, quantum-size-related properties, and applications toward biology, catalysis, and nanotechnology, Chem. Rev., 2004, 104, 293-346.

3 M. T. Islam, S. K. Molugu, P. H. Cooke and J. C. Noveron, Fullerene stabilized gold nanoparticles, New J. Chem., 2015, 39, 5923-5926.

4 M. T. Islam, J. E. Padilla, N. Dominguez, D. C. Alvarado, M. S. Alam, P. Cooke, M. M. J. Tecklenburg and J. C. Noveron, Green synthesis of gold nanoparticles reduced and stabilized by squaric acid and supported on cellulose fibers for the catalytic reduction of 4-nitrophenol in water, RSC Adv., 2016, 6, 91185-91191.

5 H. Wang, D. W. Brandl, P. Nordlander and N. J. Halas, Plasmonic Nanostructures: Artificial Molecules, Acc. Chem. Res., 2007, 40, 53-62.

$6 \mathrm{~J}$. Shan and H. Tenhu, Recent advances in polymer protected gold nanoparticles: synthesis, properties and applications, Chem. Commun., 2007, 4580-4598.

7 J. Wang, L. Wang, X. Liu, Z. Liang, S. Song, W. Li, G. Li and C. Fan, A Gold Nanoparticle-Based Aptamer Target Binding Readout for ATP Assay, Adv. Mater., 2007, 19, 3943-3946.

8 M. A. Uppal, A. Kafizas, M. B. Ewing and I. P. Parkin, The effect of initiation method on the size, monodispersity and shape of gold nanoparticles formed by the Turkevich method, New J. Chem., 2010, 34, 2906-2914.

9 S. A. Wadhwani, U. U. Shedbalkar, S. Nadhe, R. Singh and B. A. Chopade, Decolorization of textile dyes by combination of gold nanocatalysts obtained from Acinetobacter sp SW30 and NaBH4, Environ. Technol. Innov., 2018, 9, 186-197.

10 K. Vijayaraghavan and T. Ashokkumar, Plant-mediated biosynthesis of metallic nanoparticles: a review of literature, factors affecting synthesis, characterization techniques and applications, J. Environ. Chem. Eng., 2017, 5, 4866-4883.

11 A. Corma and H. Garcia, Supported gold nanoparticles as catalysts for organic reactions, Chem. Soc. Rev., 2008, 37, 2096-2126.

12 S. K. Ghosh, S. Kundu, M. Mandal and T. Pal, Silver and gold nanocluster catalyzed reduction of methylene blue by arsine in a micellar medium, Langmuir, 2002, 18, 8756-8760.

13 R. Narayanan, Synthesis of green nanocatalysts and industrially important green reactions, Green Chem. Lett. Rev., 2012, 5, 707-725.

14 K. B. Narayanan and H. H. Park, Homogeneous catalytic activity of gold nanoparticles synthesized using turnip (Brassica rapa L.) leaf extract in the reductive degradation of cationic azo dye, Korean J. Chem. Eng., 2015, 32, 1273-1277.

15 J. Turkevich, P. C. Stevenson and J. Hillier, A study of the nucleation and growth processes in the synthesis of colloidal gold, Discuss. Faraday Soc., 1951, 11, 55-75.

16 X. P. Sun, S. J. Dong and E. K. Wang, One-step synthesis and characterization of polyelectrolyte-protected gold nanoparticles through a thermal process, Polymer, 2004, 45, 2181-2184.

17 A. M. Signori, K. D. Santos, R. Eising, B. L. Albuquerque, F. C. Giacomelli and J. B. Domingos, Formation of Catalytic Silver Nanoparticles Supported on Branched Polyethyleneimine Derivatives, Langmuir, 2010, 26, 17772-17779.

18 S. M. Louie, J. M. Gorham, J. Tan and V. A. Hackley, Ultraviolet photo-oxidation of polyvinylpyrrolidone (PVP) coatings on gold nanoparticles, Environ. Sci.: Nano, 2017, 4, 1866-1875.

19 P. Vicennati, A. Giuliano, G. Ortaggi and A. Masotti, Polyethylenimine in Medicinal Chemistry, Curr. Med. Chem., 2008, 15, 2826-2839.

20 U. Lungwitz, M. Breunig, T. Blunk and A. Göpferich, Polyethylenimine-based non-viral gene delivery systems, Eur. J. Pharm. Biopharm., 2005, 60, 247-266.

21 T. N. J. I. Edison, R. Atchudan, M. G. Sethuraman and Y. R. Lee, Reductive-degradation of carcinogenic azo dyes using Anacardium occidentale testa derived silver nanoparticles, J. Photochem. Photobiol., B, 2016, 162, 604-610.

22 M. F. Hou, F. B. Li, X. M. Liu, X. G. Wang and H. F. Wan, The effect of substituent groups on the reductive degradation of azo dyes by zerovalent iron, J. Hazard. Mater., 2007, 145, 305-314.

23 R. Rajesh, S. S. Iyer, J. Ezhilan, S. S. Kumar and R. Venkatesan, Graphene oxide supported copper oxide nanoneedles: an efficient hybrid material for removal of toxic azo dyes, Spectrochim. Acta, Part A, 2016, 166, 49-55.

24 K. Yamjala, M. S. Nainar and N. R. Ramisetti, Methods for the analysis of azo dyes employed in food industry - a review, Food Chem., 2016, 192, 813-824.

25 Y. Zhang, F. Gao, B. Wanjala, Z. Y. Li, G. Cernigliaro and Z. Y. Gu, High efficiency reductive degradation of a wide 
range of azo dyes by $\mathrm{SiO}_{2}$-Co core-shell nanoparticles, Appl. Catal., B, 2016, 199, 504-513.

26 M. A. Brown and S. C. Devito, Predicting Azo-Dye Toxicity, Crit. Rev. Environ. Sci. Technol., 1993, 23, 249-324.

27 Z. U. Khan, A. Khan, Y. M. Chen, A. U. Khan, N. S. Shah, N. Muhammad, B. Murtaza, K. Tahir, F. U. Khan and P. Y. Wan, Photo catalytic applications of gold nanoparticles synthesized by green route and electrochemical degradation of phenolic Azo dyes using AuNPs/GC as modified paste electrode, J. Alloys Compd., 2017, 725, 869-876.

28 S. Joseph and B. Mathew, Microwave-assisted green synthesis of silver nanoparticles and the study on catalytic activity in the degradation of dyes, J. Mol. Liq., 2015, 204, 184-191.

29 I. A. Alaton and I. A. Balcioglu, Photochemical and heterogeneous photocatalytic degradation of waste vinylsulphone dyes: a case study with hydrolysed Reactive Black 5, J. Photochem. Photobiol., A, 2001, 141, 247-254.

30 M. Faisal, M. Abu Tariq and M. Muneer, Photocatalysed degradation of two selected dyes in UV-irradiated aqueous suspensions of titania, Dyes Pigm., 2007, 72, 233-239.

31 Y. Y. Qu, W. L. Shen, X. F. Pei, F. Ma, S. N. You, S. Z. Li, J. W. Wang and J. T. Zhou, Biosynthesis of gold nanoparticles by Trichoderma sp WL-Go for azo dyes decolorization, J. Environ. Sci., 2017, 56, 79-86.

32 X. You, C. Huang, W. Huang, G. Shi, J. Deng and T. Zhou, Ultra-small $\mathrm{CoO}_{x} / \mathrm{GO}$ catalyst supported on ITO glass obtained by electrochemical post-treatment of a redoxactive infinite coordination polymer: a portable reactor for real-time monitoring of catalytic oxidative degradation of colored wastewater, Environ. Sci.: Nano, 2020, 7, 554-570.

33 K. Simeonidis, S. Mourdikoudis, E. Kaprara, M. Mitrakas and L. Polavarapu, Inorganic engineered nanoparticles in drinking water treatment: a critical review, Environ. Sci.: Water Res. Technol., 2016, 2, 43-70.

34 Y. X. Zhang, X. D. Hao, F. Li, Z. P. Diao, Z. Y. Guo and J. Li, $\mathrm{pH}$-Dependent Degradation of Methylene Blue via RationalDesigned $\mathrm{MnO}_{2}$ Nanosheet-Decorated Diatomites, Ind. Eng. Chem. Res., 2014, 53, 6966-6977.

35 Q. Xiao, J. Zhang, C. Xiao, Z. Si and X. Tan, Solar photocatalytic degradation of methylene blue in carbon-doped $\mathrm{TiO}_{2}$ nanoparticles suspension, Sol. Energy, 2008, 82, 706-713.

36 V. S. Suvith and D. Philip, Catalytic degradation of methylene blue using biosynthesized gold and silver nanoparticles, Spectrochim. Acta, Part A, 2014, 118, 526-532.

37 N. Gupta, H. P. Singh and R. K. Sharma, Metal nanoparticles with high catalytic activity in degradation of methyl orange: an electron relay effect, J. Mol. Catal. A: Chem., 2011, 335, 248-252.

38 R. K. Sharma, P. Sharma and A. Maitra, Size-dependent catalytic behavior of platinum nanoparticles on the hexacyanoferrate(III)/thiosulfate redox reaction, J. Colloid Interface Sci., 2003, 265, 134-140.

39 C. Umamaheswari, A. Lakshmanan and N. S. Nagarajan, Green synthesis, characterization and catalytic degradation studies of gold nanoparticles against congo red and methyl orange, J. Photochem. Photobiol., B, 2018, 178, 33-39.

40 B. R. Ganapuram, M. Alle, R. Dadigala, A. Dasari, V. Maragoni and V. Guttena, Catalytic reduction of methylene blue and Congo red dyes using green synthesized gold nanoparticles capped by salmalia malabarica gum, Int. Nano Lett., 2015, 5, 215-222.

41 K. D. Santos, W. C. Elias, A. M. Signori, F. C. Giacomelli, H. Yang and J. B. Domingos, Synthesis and Catalytic Properties of Silver Nanoparticle-Linear Polyethylene Imine Colloidal Systems, J. Phys. Chem. C, 2012, 116, 4594-4604.

42 Y. K. Long, L. Xiao and Q. H. Cao, Co-polymerization of catechol and polyethylenimine on magnetic nanoparticles for efficient selective removal of anionic dyes from water, Powder Technol., 2017, 310, 24-34.

43 B. Chen, Y. Liu, S. Chen, X. Zhao, W. Yue and X. Pan, Nitrogen-rich core/shell magnetic nanostructures for selective adsorption and separation of anionic dyes from aqueous solution, Environ. Sci.: Nano, 2016, 3, 670-681.

44 W.-H. Kuan and Y.-C. Chan, pH-dependent mechanisms of methylene blue reacting with tunneled manganese oxide pyrolusite, J. Hazard. Mater., 2012, 239-240, 152-159.

45 V. Kafil and Y. Omidi, Cytotoxic impacts of linear and branched polyethylenimine nanostructures in a431 cells, Bioimpacts, 2011, 1, 23-30.

46 M. Hecold, R. Buczkowska, A. Mucha, J. Grzesiak, O. RacRumijowska, H. Teterycz and K. Marycz, The Effect of PEI and PVP-Stabilized Gold Nanoparticles on Equine Platelets Activation: Potential Application in Equine Regenerative Medicine, J. Nanomater., 2017, 2017, 8706921.

47 Q. Tang, F. Cheng, X. L. Lou, H. J. Liu and Y. Chen, Comparative study of thiol-free amphiphilic hyperbranched and linear polymers for the stabilization of large gold nanoparticles in organic solvent, J. Colloid Interface Sci., 2009, 337, 485-491.

48 O. Cavuslar, C. Celaloglu, F. D. Duman, Y. U. Konca, M. B. Yagci and H. Y. Acar, pH and molecular weight dependence of auric acid reduction by polyethylenimine and the gene transfection efficiency of cationic gold nanoparticles thereof, New J. Chem., 2018, 42, 10078-10083.

49 F. Kretschmer, U. Mansfeld, S. Hoeppener, M. D. Hager and U. S. Schubert, Tunable synthesis of poly (ethylene imine)gold nanoparticle clusters, Chem. Commun., 2014, 50, 88-90.

50 S. Mourdikoudis, M. Chirea, T. Altantzis, I. Pastoriza-Santos, J. Pérez-Juste, F. Silva, S. Bals and L. M. Liz-Marzán, Dimethylformamide-mediated synthesis of water-soluble platinum nanodendrites for ethanol oxidation electrocatalysis, Nanoscale, 2013, 5, 4776-4784.

51 S. Mourdikoudis, V. Montes-García, S. Rodal-Cedeira, N. Winckelmans, I. Pérez-Juste, H. Wu, S. Bals, J. Pérez-Juste and I. Pastoriza-Santos, Highly porous palladium nanodendrites: wet-chemical synthesis, electron tomography and catalytic activity, Dalton Trans., 2019, 48, 3758-3767.

52 P. L. Kuo, C. C. Chen and M. W. Jao, Effects of polymer micelles of alkylated polyethylenimines on generation of gold nanoparticles, J. Phys. Chem. B, 2005, 109, 9445-9450. 
53 C. C. Chen and P. L. Kuo, Gold nanoparticles prepared using polyethylenimine adsorbed onto montmorillonite, J. Colloid Interface Sci., 2006, 293, 101-107.

54 K. A. Curtis, D. Miller, P. Millard, S. Basu, F. Horkay and P. L. Chandran, Unusual Salt and $\mathrm{pH}$ Induced Changes in Polyethylenimine Solutions, PLoS One, 2016, 11, e0158147.

55 M. M. Maye, W. X. Zheng, F. L. Leibowitz, N. K. Ly and C. J. Zhong, Heating-induced evolution of thiolate-encapsulated gold nanoparticles: a strategy for size and shape manipulations, Langmuir, 2000, 16, 490-497.

56 M. J. R. G. R. Pires, M. I. A. Ferra and A. M. M. Marques, Ionization of methyl orange in aqueous sodium chloride solutions, J. Chem. Thermodyn., 2012, 53, 93-99.

57 K. Basavaiah, Application of bromate-bromide mixture and methyl orange in the titrimetric, spectrophotometric and kinetic assay methods for cyproheptadine in pharmaceuticals, Indian J. Chem. Technol., 2006, 13, 360-366.

58 Y. C. Pei, J. J. Wang, X. P. Xuan, J. Fan and M. H. Fan, Factors affecting ionic liquids based removal of anionic dyes from water, Environ. Sci. Technol., 2007, 41, 5090-5095.

59 D. Melgoza, A. Hernandez-Ramirez and J. M. PeraltaHernandez, Comparative efficiencies of the decolourisation of Methylene Blue using Fenton's and photo-Fenton's reactions, Photochem. Photobiol. Sci., 2009, 8, 596-599.

60 L. P. Nguyen and N. S. Gerstein, in Essentials of Cardiac Anesthesia for Noncardiac Surgery, ed. J. A. Kaplan, B. Cronin and T. M. Maus, Content Repository Only!, New York, 2019, pp. 247-288, DOI: 10.1016/B978-0-32356716-9.00011-4.

61 A. J. Néel, M. J. Hilton, M. S. Sigman and F. D. Toste, Exploiting non-covalent pi interactions for catalyst design, Nature, 2017, 543, 637-646.

62 T. Steiner and G. Koellner, Hydrogen bonds with pi-acceptors in proteins: frequencies and role in stabilizing local 3D structures, J. Mol. Biol., 2001, 305, 535-557.

63 E. Omanovic-Miklicanin, I. Manfield and T. Wilkins, Application of isothermal titration calorimetry in evaluation of protein-nanoparticle interactions, J. Therm. Anal. Calorim., 2017, 127, 605-613.

64 Y. Kaconis, I. Kowalski, J. Howe, A. Brauser, W. Richter, I. Razquin-Olazaran, M. Inigo-Pestana, P. Garidel, M. Rossle, G. M. de Tejada, T. Gutsmann and K. Brandenburg, Biophysical Mechanisms of Endotoxin Neutralization by Cationic Amphiphilic Peptides, Biophys. J., 2011, 100, 2652-2661. 